\title{
Virus and Virus-like Diseases of Strawberry
}

\author{
R.H. Converse \\ United States Department of Agriculture, Agricultural Research Service, Horticultural Crops Research Unit, \\ Oregon State University, Cowallis, OR 97331
}

Virus and virus-like diseases have an enormous impact on strawberry production throughout the United States. They influence and may limit the choice of parental lines for plant breeders. They are responsible for many of the special management methods used by nurseries to provide growers with certified planting stock from virus-tested sources. They are a major source of yield loss in fruiting fields. In this review, two main questions will be addressed: 1) What progress has been made recently in detecting and determining the cause of the noninfectious disease called June yellows and in detecting and characterizing the virus and virus-like agents that cause eight major infectious diseases of cultivated strawberry on the U.S. Pacific Coast?, and 2) How well are these diseases currently being controlled, and what of the future?

\section{Pacific Coast strawberry virus and virus-like disease analysis and detection}

The eight most economically important virus and virus-like diseases of strawberry on the Pacific Coast are June yellows, strawberry mottle, strawberry vein banding, strawberry crinkle, strawberry mild yellow-edge, tomato ringspot, tobacco streak (also known in strawberry as necrotic shock disease), and pallidosis. They are grouped here by their method of natural spread in the. field, although all eight occur in daughter plants that are vegetatively propagated from runners (stolons) of diseased strawberry plants. These diseases and their causal agents have been the subjects of two recent reviews (Converse, 1987; Converse et al., 1988). The first reference contains numerous color illustrations of symptoms of the major strawberry viruses on diagnostic hosts. Except where specifically noted, the reader may consult these two references for the relevant original literature in this field.

June yellows $(J y)$. This is a nonpathogenic disorder, probably of genetic origin, that spreads naturally only through runners, pollen, or seed from a JY-infected plant. No pathogen nor unique nucleic acid has been consistently associated with JY. Double-stranded RNA (dsRNA), not found in healthy plants, has been found in JY plants, but erratically and in varying sizes. Transmission of JY between two plants not of the same vegetative clone occurs only sexually, and the appearance of symptoms in resulting seedlings may be delayed for several seasons. A strawberry cultivar with symptoms of JY usually has lower plant vigor. Bringhurst and Voth (1989) documented a $43 \%$ yield loss in the California cultivar Tufts with JY compared to symptomless 'Tufts'. To avoid the development of JY in their selections, plant breeders try to select parents with ancestries as free from JY as possible. Since no bioassay or biochemical test has yet been devised for reliable detection of JY in strawberry plants in which JY may be latent, plant breeders may evaluate their parental lines by crossing them to cultivars such as 'Tufts', or 'Tardive de Leopold', as suggested by Wills (1962)-genotypes that favor the expression of JY symptoms in their offspring. Obviously, the existence of JY in certain breeding lines and the present inability to detect or eliminate it constitute major impediments to the use of otherwise desirable parents in strawberry plant breeding.

\section{Methods of detection of viruses}

The four Pacific Coast strawberry viruses that are aphid-transmitted are naturally restricted to the genus Fragaria, where they

\footnotetext{
Cooperative research between U.S. Dept. of Agriculture, Agricultural Research Service, and the Oregon Agricultural Experiment Station, Technical Communication number 8881 of the latter.

'Research Plant Pathologist.
}

are very common and damaging. However, they rarely produce diagnostic symptoms in cultivated strawberries. Therefore, indirect detection methods must be used, such as graft or sap transmission to susceptible hosts that will produce diagnostic symptoms if infected, or specific serological or biochemical detection tests, when available. Leaflet graft transmission to sensitive Fragaria seedlings or clones is currently the standard method for detection of these viruses. In this method, reported by Bringhurst and Voth (1956), leaflets from suspect strawberry plants are grafted into petioles of sensitive Fragaria indicator plants. Frazier (1974a, 1974b) subsequently modified the method and released the very virus-sensitive $F$. vesca clones UC-4, 5, and 6 , and the $F$. virginiana clones UC10,11 , and 12 . Production of diagnostic symptoms usually occurs within 4 to 6 weeks after grafting. Converse and Tanne (1984) studied reliability of detection of one isolate of the aphid-borne virus, strawberry mild yellow-edge, by leaflet grafting. They found that it was necessary to obtain negative (symptomless) results after grafting to three plants of a $F$. vesca indicator in order to state with $99 \%$ confidence that the source plant was free of this virus. Similarly reliable tests are lacking for other aphid-borne strawberry viruses, but it is certainly prudent to use iteration in strawberry virus detection by leaf graft analysis when attempting to demonstrate that a given clone is free from known viruses. Variability in virus strains, in the virus level in the donor plant, in the sensitivity of the indicator plants, and in the influence of the greenhouse environment before and during the 6-week bioassay symptom evaluation period all contribute to the uncertainty of the graft analysis procedure. Thus, such assays should be repeated frequently when they are negative, and should always be accompanied by appropriate grafts to the same indicator clone from a known source of the same virus and the grafting of healthy leaves back to healthy indicator plants as negative controls.

Strawberry mottle virus $(S M V)$. This disease is transmitted in a semipersistent manner by the common strawberry aphid [ Chaetosiphon fragaefolii (Ckll.)] and other aphids. Although it has been successfully sap-transmitted from strawberry to the herbaceous host, Chenopodium quinoa Willd., and from that host back to strawberry by $C$. fragifolii to produce characteristic symptoms, the identity and relationships of the associated virus(es) have not yet been clearly established. Bioassay by sap inoculation to C. quinoa is too insensitive to be used as a reliable method of detecting SMV. The detection procedure recommended currently is still greenhouse bioassay by leaflet insert grafting. A rapid, accurate serological or biochemical procedure is needed badly for the routine detection of SMV in cultivated strawberries.

Strawberry vein banding virus (SVSV). This is a double-stranded DNA caulimovirus semipersistently transmitted by $C$. fragaefolii and other aphids. Full-length clones of the viral genome have been prepared and have been shown to be sensitive detection probes for this virus in infected strawberry plants in dot blot tests. Although this procedure is new, we can expect it to become progressively more available for routine testing for SVBV in the future. Meanwhile, the standard $F$. vesca indicator clones useful for SMV are also suitable for detection of SVBV by leaflet graft bioassay. However, the presence of other aphid-borne viruses, such as SMV in the same source plant, may interfere with the production of recognizable SVBV symptoms on grafted $F$. vesca.

Strawberry crinkle virus ( $S C V$ ). This is a cytoplasmic rhabdovirus persistently transmitted by $C$. fragaefolii aphids for the life of the infected insect. SCV is normally limited to infecting plants of the genus Fragaria. Recent experimental transmissions were successfully made to herbaceous hosts in the genera Nicotiana and Physalis 
by injecting haemolymph ("insect blood") from viruliferous $C$. fragaefolii into aphids like Macrosiphum euihorbiae (Thomas) that have a broader food plant range and by using these injected aphids to infect the host plants. Certain biotinylated lectins have been used successfully to detect SCV from partially purified, infected herbaceous host tissue. Progress is also being made toward development of biochemical and serological probes that will detect SCV in strawberry cultivars. Until such probes become widely available, leaf grafting to sensitive $F$. vesca indicators remains the detection method of choice.

Strawberry mild yellow-edge virus (SMYEV). This ssRNA virus is persistently transmitted by $C$. fragaefolii for the life of the infected aphid. The virus has been reported to be a member of the phloem-limited luteovirus group with an isometric particle diameter variously reported from 22 to $30 \mathrm{~nm}$. Bands of dsRNA at relative molecular masses of 3.8, 2.8, and 1.3 million Da were found in SMYEV-infected, but not in healthy strawberry tissue. Although these dsRNA bands resemble those found in other better-characterized luteoviruses, at present, $20 \mathrm{~g}$ of fresh tissue are required in the preparation of visible dsRNA bands from strawberry. Even though valuable for research purposes, the method (Spiegel, 1987) is very time consuming, is not sufficiently sensitive for reliable determination of the absence of these bands in a strawberry clone, and is unsuitable for routine testing. Therefore, leaf graft analysis to $F$. vesca seedlings or clones is the standard method of detection of this virus. The $F$. vesca clone UC-6 is particularly valuable in the identification of strawberry mild yellow-edge disease. It fails to produce strong symptoms when graft-inoculated from plants having only this disease, although the other major aphid-borne strawberry viruses do produce symptoms on UC-6 (Frazier, 1974b).

Tomato ringspot virus (TmRSV). This is a nepovirus transmitted by the American dagger nematodes, Xiphinema rivesi Dalmasso, $X$. americanum Cobb, and possibly some other related Xiphinema spp. Both TmRSV and its vector nematodes have very large host ranges in crop and weed plants. Like other nepoviruses, TmRSV depends on vector nematodes for short-distance spread, but is spread long distances in seed and pollen in many host species, including strawberry, where infected seedlings are symptomless. Good polyclonal and monoclonal antisera have been developed against TmRSV that can be purchased commercially for routine identification (e.g., from American Type Culture Collection Rockville, Md.). Commonly used serological tests, such as the double antibody sandwich enzyme-linked immunosorbent assay (DAS-ELISA) (Clark, 1981), quickly and accurately detect. TmRSV in infected strawberry cultivars, and are the tests of choice for this virus. TmRSV is saptransmitted with some difficulty from infected strawberry leaves to herbaceous test plants. Confirmatory serological identification by ELISA is readily accomplished from leaves of infected strawberry or herbaceous hosts. The common $F$. vesca indicator plants develop characteristic symptoms when inoculated with TmRSV by leaflet grafting.

Strawberry isolates of tobacco streak virus (TSV-S). This is an ilarvirus, spread in strawberry fields by unknown means. Some other strains of TSV are reported to be transmitted by thrips (e.g., Frankliniella and Thrips spp.). In strawberry, TSV-S is both eggand pollen-borne. Either infected gamete can cause seed-borne transmission of TSV-S, but infected pollen does not infect the pollinated mother plant. Detection of TSV-S in infected strawberry by ELISA or by cDNA probes is rapid and accurate. Antisera for ELISA are available commercially that will recognize TSV-S (e.g., antisera against the bean red node strain of tobacco streak virus from the American Type Culture Collection). TSV-S is difficult to transmit mechanically from strawberry to herbaceous hosts, but is easily 'transmitted by leaflet graft to standard F. vesca indicator plants.

Pallidosis disease agent (PDA). This is probably a virus, but its identity is still unconfirmed. It spreads by unknown means in the field and the greenhouse. Although there is great variability among PDA isolates of the relative molecular masses of their dsRNA bands, all isolates so far studied have two to four dsRNA bands ranging from 4.3 to 4.8 million Da (Yoshikawa and Converse, 1990). dsRNA bands characteristic of PDA have recently been identified in some standard clones of UC-4, 5, and 6 (Yoshikawa and Converse, 1990). The effects of these PDA isolates on the sensitivity of these indicators to other viruses is still under study.

The standard method of detection of PDA is by leaflet grafting to sensitive clones of $F$. virginiana L., such as UC-10. Because many other strawberry viruses produce symptoms on $F$. virginiana by leaf grafting that are indistinguishable from those produced by PDA, graft analysis for PDA is not feasible from cultivated strawberries with multiple virus infections. PDA interacts with some isolates of SMYEV to intensify symptoms in Fragaria indicator plants.

Among the eight virus and virus-like diseases discussed in this review, the detection of PDA is least well-developed, particularly from complex infections. At present, the extraction of dsRNA from suspect plants with complex virus infection followed by subsequent identification of dsRNA bands in the 4.3 to 4.8 million Da range is a possible new method for PDA detection. Similar to other dsRNA detection methods, negative evidence from such tests should be evaluated with caution.

\section{Control of virus and virus-like diseases of strawberry on the Pacific Coast}

Because of the high value of the strawberry fruit crop, the high costs of production, and the severe crop losses that virus and viruslike diseases (hereafter simply called viruses) can cause, control procedures are an important element in overall strawberry farm management. Control procedures can be grouped into three categories: 1) virus elimination, 2) vector control, and 3) use of cultivars that are vector-resistant, virus-resistant, or virus-tolerant. These categories are not mutually exclusive, and successful commercial management of virus diseases makes use of all of them.

1) Virus elimination. All eight of the strawberry diseases discussed above occur. in the daughter plants of infected mother plants. Therefore, a major point of control of these diseases is in the strawberry nursery. By use of clonal selection, heat therapy, regeneration following shoot apex tissue culture, and subsequent virus indexing, clones of the major Pacific Coast strawberry cultivars have been developed that are free from major viruses. These basic virus-tested clones are maintained, generally by public agencies, in tissue culture or in screened, insect-proof, insecticide-treated enclosures. Their daughter plants or tissue-cultured proliferants are distributed to private nurseries through certification schemes administered by state departments of agriculture. Plants are then increased under prescribed conditions of previous crop history, soil fumigation, minimum or greater geographic isolation from field-run strawberry plants, and duration of planting. The use of certified strawberry planting stocks has been of tremendous benefit in reducing virus damage in fruiting fields. In areas of California where strawberries are grown as an annual crop, the benefits of using certified planting stock, essentially free from known viruses, are particularly noticeable because the lag time required after virus infection for economic crop damage to occur often exceeds the length of time the crop is in the field.

There appear to be certain, poorly characterized, latent viruses that are difficult to eliminate by combinations of heat therapy and shoot apex tissue culture used currently. As more-sensitive virus detection methods become available, it may be necessary to refine present virus elimination techniques, perhaps including chemotherapeutants, to eliminate such viruses while preserving the innate genetic integrity of the treated strawberry clone.

2) Vector control. For viruses that spread by unknown means in strawberry fields, such as tobacco streak and pallidosis, additional research is needed to determine if vectors are involved in their spread and, if so, to identify them.

For the four viruses that are primarily spread in the field by the aphid Chaetosiphon fragaefolii, reasonable virus control can be achieved by selecting planting sites that are distant (kilometers, not meters) from uncertified, unsprayed strawberry fields. Alternatively, entomologists have long advocated area-wide application of approved aphicides to strawberry fields to reduce vector aphid populations within the fields and reduce the populations of winged aphids migrating to new fields. The complete cooperation among 
growers in an area that is needed for effective area-wide vector aphid control schemes is difficult to obtain. Aphid-borne strawberry viruses are so difficult to control by spraying because many apihicides that are very effective in killing aphids do so too slowly to prevent them from infecting plants before the aphids die. Certain aphicides, including several synthetic pyrethroids, have shown promise in experimental plots by reducing virus levels to half those of adjoining unsprayed plots (Converse and AliNiazee, 1988). Various other biological, economic, and sociological factors must also be taken into consideration before such experimental observations can be found to have commercial applicability.

Tomato ringspot virus appears to move so slowly in strawberry fields that it is unlikely to become an economic problem in annually planted fields or in fields preplant-fumigated with any one of a number of nematicides. In the Pacific Northwest, this virus and its dagger nematode vectors are common enough in red raspberry fields to make it advisable not to plant strawberries directly after tomatoringspot-vi\&-infected red raspberries without first fumigating the land with a suitable nematicide. If the present reduction in the number of permissible soil fumigants continues, we may expect populations of dagger nematodes to increase in strawberry fields in the future, and the threat of tomato ringspot virus damage in strawberry to increase from its present low level.

3) Use of virus/vector-resistant and -tolerant cultivars. Great strides have been made in identifying and incorporating effective levels of genetic resistance and tolerance to major strawberry viruses and to their vectors, but there is much left to do. The inadequacy and often the increasing unavailability of alternate control procedures make the genetic approach to virus disease control increasingly attractive. At the same time, the growing number of techniques for moving genes among related plant species, and even by molecular biological techniques among remote taxa, offer new opportunities for incorporating desirable disease or vector-resistance genes into strawberry germplasm in the future.

For June yellows, the need for a thorough understanding, leading to management, of this disease in strawberry plant breeding has previously been discussed. Until this problem is solved, it will also impede the progress of control of strawberry viruses and their vectors by genetic means.

For the four aphid-borne viruses. The evaluation of parental breeding lines and field selection of seedlings has brought about the development of several Pacific Coast strawberry cultivars with high levels of tolerance to these four common strawberry viruses. Virus tolerance is almost automatically selected for in Pacific Coast strawberry plant breeding plots because no immunity to these viruses is known to occur in the cultivated strawberry, and seedlings that do not have a high level of tolerance to these ever-present viruses do not grow vigorously enough to be selected. Work recently reviewed by Shanks and Sjulin (1988) reveals methods for introducing resistance to colonization by the aphid $C$. fragaefolii from Fragaria chiloensis to hybrids with cultivated strawberry. Hybrids carrying this genetic resistance to colonization by $C$. fragaefolii rarely become virus-infected by this aphid vector, although they are still graft-susceptible. None of these hybrids is sufficiently close to the cultivated strawberry type horticulturally to be named and released, but this work opens an important new avenue to control of the viruses that are vectored only by this aphid. The role of other aphid species in the spread of strawberry viruses still requires more study.

Tomato ringspot virus. Resistance in Pacific Coast strawberry cultivars is unusual in its variability, ranging from extreme susceptibility (e.g., 'Benton', 'Hood', 'Sequoia', 'Totem', and 'Tufts'), through intermediate resistance (e.g., 'Brighton', 'Douglas', 'Ranier', and 'Shuksan') to immune (e.g. 'Northwest', 'Quinault', and several eastern U.S. cultivars) (Converse, 1986). Very likely, sufficient immune germplasm is available in quality cultivars to make possible the development of horticulturally superior TmRSV-immune cultivars that are adapted to the varying requirements for strawberry growing on the U.S. Pacific Coast, and elsewhere when they are needed.

Tobacco streak virus and pallidosis agent. Both are common and damaging enough in Pacific Coast strawberry fields to warrant a more thorough search of the genus Fragaria for sources of resistance or tolerance to these pathogens. Tobacco streak virus is a special problem to plant breeders because it is transmitted to seedlings from either infected parent.

\section{Literature Cited}

Bringhurst, R.S. and V. Voth. 1956. Strawberry virus transmission by grafting excised leaves. Plant Dis. Rptr. 40:596-600.

Bringhurst, R.S. and V. Voth. 1989. California strawberry cultivars. Fruit Var. J. 43:12-19.

Clark, M.F. 1981. Immunosorbent assays in plant pathology. Annu. Rev. Phytopathol. 19:83-106.

Converse, R.H. 1986. Susceptibility of some strawberry cultivars to tomato ringspot virus as determined by ELISA. Plant Dis. 70:369-371.

Converse, R.H. (ed.). 1987. Virus diseases of small fruits. U.S. Dept. of Agriculture, Agr. Hdbk. 631.

Converse, R.H., A.N. Adams, D.J. Barbara, M.F. Clark, R. Casper, R.F Hepp, R.R. Martin, T.J. Morris, S. Spiegel, and N. Yoshikawa. 1988. Laboratory detection-of viruses and mycoplasmalike organisms in strawberry. Plant Dis. 72:744-749.

Converse, R.H. and M.T. AliNiazee. 1988. Effects of insecticides applied in the field on incidence of aphid-borne viruses in cultivated strawberry. Plant Dis. 72:127-129.

Converse, R.H. and E. Tanne. 1984. Heat therapy and stolon apex culture to eliminate mild yellow-edge virus from Hood strawberry. Phytopathology 74:1315-1316.

Frazier, N.W. 1974a. Detection of graft-transmissible diseases in strawberry by a modified leaf grafting technique. Plant Dis. Rptr. 58:203-207.

Frazier, N.W. 1974b. Six new strawberry indicator clones evaluated for the detection and diagnosis of twelve graft-transmissible diseases. Plant Dis. Rptr. 58:28-31.

Shanks, C.H., Jr., and T.M. Sjulin. 1988. The entomology of indigenous and naturalized systems in agriculture, D. 91-98 In: M.K. Harris and C.R. Rogers (eds.). The entomology of indigenous and naturalized systems in agriculture (Westview studies in insect biology). Westview, Boulder, Colo.

Spiegel, S. 1987. Double-stranded RNA in strawberry plants infected with strawberry mild yellow-edge virus. Phytopathology 77:1492-1494.

Wills, A.B. 1962. Genetical aspects of strawberry June yellows. Heredity 17:361-372.

Yoshikawa, N. and R.H. Converse. 1990. Double-stranded RNAs in pallidosis-diseased strawberry and Fragaria species. Phytopathology 79:912. (Abstr.) 